\title{
Role of Cardiac Imaging: Cardiac Magnetic Resonance and Cardiac Computed Tomography
}

\author{
Giancarlo Vitrella, Giorgio Faganello, Gaetano Morea, \\ Lorenzo Pagnan, Manuel Belgrano, \\ and Maria Assunta Cova
}

\section{Abbreviations and Acronyms}

2D

CAD

CCT

CMR

CRT

CT

CTCA

DCM

ECV

FFR

GRE

HF

ICD

LAV

LGE

LIE

LLC

LV

LVEF
Two-dimensional

Coronary artery disease

Cardiac computed tomography

Cardiac magnetic resonance

Cardiac resynchronization therapy

Computed tomography

Computed tomography coronary angiography

Dilated cardiomyopathy

Extracellular volume

Fractional flow reserve

Global relative enhancement

Heart failure

Implantable cardioverter-defibrillator

Left atrial volume

Late gadolinium enhancement

Late iodine enhancement

Lake Louise criteria

Left ventricular

Left ventricular ejection fraction

G. Vitrella $(\varangle) \cdot$ G. Faganello $~ \cdot$ G. Morea

Cardiovascular Department, Azienda Sanitaria Universitaria Integrata di Trieste (ASUITS),

Trieste, Italy

e-mail: giorgio.faganello@asuits.sanita.fvg.it

L. Pagnan · M. Belgrano · M. A. Cova

Diagnostic and Interventional Radiology Department, Azienda Sanitaria Universitaria

Integrata di Trieste (ASUITS), Trieste, Italy

e-mail: manuel.belgrano@asuits.sanita.fvg.it; cova@gnbts.univ.trieste.it 


$\begin{array}{ll}\text { LVRR } & \text { Left ventricular reverse remodeling } \\ \text { MOLLI } & \text { Modified look-locker inversion recovery } \\ \text { RV } & \text { Right ventricular } \\ \text { RVEF } & \text { Right ventricular ejection fraction } \\ \text { SAPPHIRE } & \text { Saturation pulse prepared heart rate-independent inversion recovery } \\ \text { SASHA } & \text { Saturation recovery single-shot acquisition } \\ \text { SCD } & \text { Sudden cardiac death } \\ \text { Sh-MOLLI } & \text { Shortened modified look-locker inversion recovery } \\ \text { SSFP } & \text { Steady-state free precession } \\ \text { STIR } & \text { Short tau inversion recovery }\end{array}$

\subsection{Cardiac Magnetic Resonance}

Cardiac magnetic resonance (CMR) has become an extensively validated noninvasive diagnostic imaging tool. Through its ability to assess cardiac morphology and function, and to characterize myocardial tissue in a reliable and reproducible fashion, it plays a pivotal role in the management of patients with dilated cardiomyopathy (DCM). In particular, it increases diagnostic accuracy and it aids in determining the etiology of left ventricular (LV) dysfunction and in prognostic stratification.

\subsection{Diagnostic Accuracy}

Steady-state free precession (SSFP) sequences are cornerstone sequences in CMR. Owing to their elevated spatial, temporal, and contrast resolution and lesser approximation in delineating endocardial borders than two-dimensional (2D) echocardiography, they minimize operator dependence and variability of intraand interobserver reproducibility. SSFP cine imaging is currently regarded as the gold standard imaging technique for the evaluation of LV volume and systolic function [1, 2], as it is not affected by the geometric assumptions used in 2D echocardiography for the LV (such as the area-length method) [3] (Fig. 8.1). In addition, the precise identification of endocardial borders allows more accurate and reliable evaluation of the extent of non-compacted myocardium than does $2 \mathrm{D}$ echocardiography, thus allowing a more precise diagnosis of myocardial noncompaction [4] (Fig. 8.2). CMR also allows for accurate and reproducible, noninvasive measurement of the left atrial $[5,6]$ and right ventricular volume and function $[7,8]$.

LV thrombus is a potential complication of severe LV dysfunction. Late gadolinium enhancement (LGE) CMR imaging is the most accurate imaging modality to detect left ventricular thrombus [9], in particular when acquiring LGE sequences with a long inversion time (compared to that needed to null normal myocardium) in order to selectively null the avascular thrombus [10] (Fig. 8.3). 

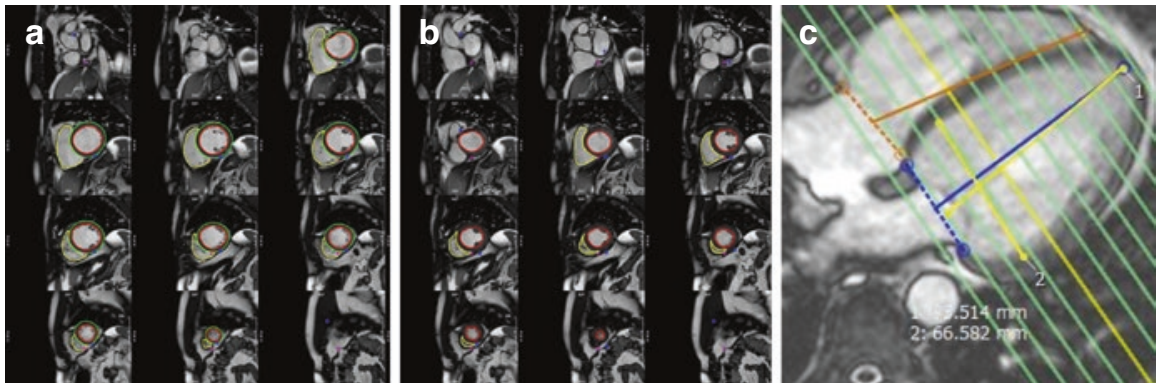

Fig. 8.1 Calculation of LV- and RVEF in MR with SSFP cine sequences. Diastolic (a) and systolic (b) endocardial contours are outlined in multislice short-axis cine runs covering the entirety of the ventricles (c); slices are $8-10 \mathrm{~mm}$ apart. Diastolic and systolic volumes are thus obtained
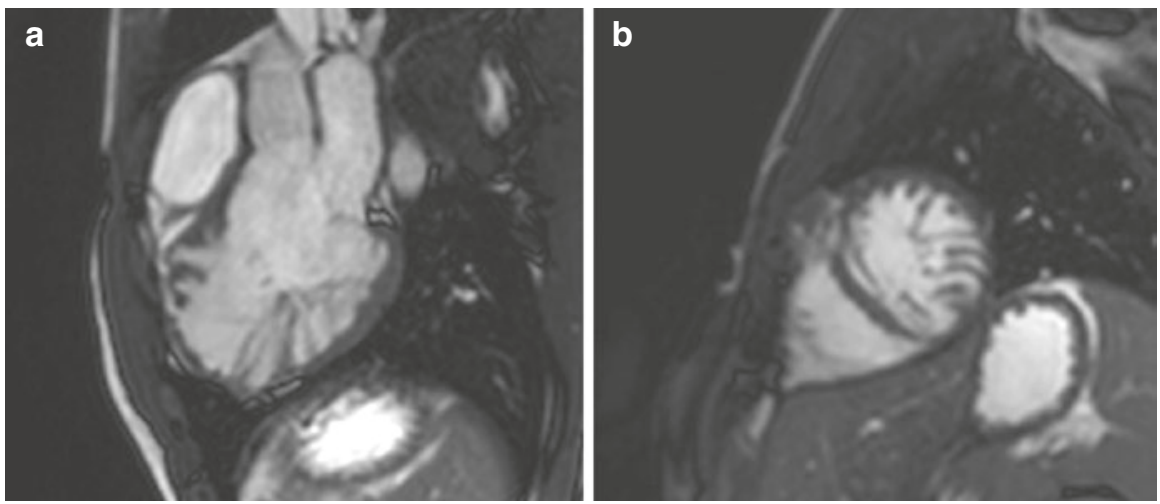

Fig. 8.2 SSFP imaging of left ventricular non-compaction in three-chamber (a) and short-axis (b) views
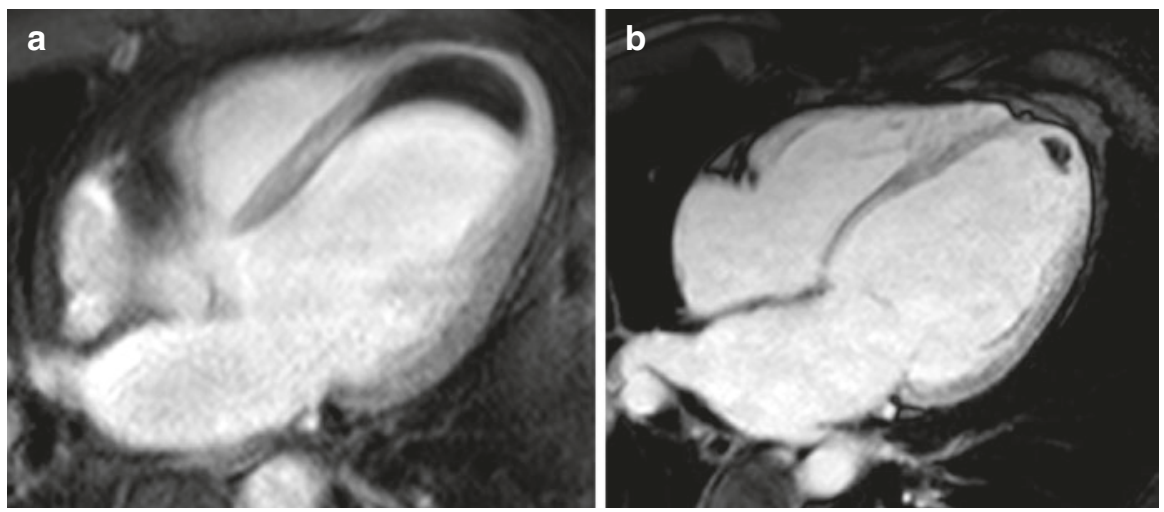

Fig. 8.3 Inversion recovery images with long inversion time in four chamber of the left ventricular thrombus in patients with left ventricular dysfunction secondary to myocardial infarction (a), and myocarditis presenting as heart failure (b) 


\subsection{Differential Diagnosis}

DCM is a condition characterized by LV dilatation and dysfunction and may represent the end stage of multiple cardiac disease processes of different etiology. The origin may be ischemic, inflammatory, infectious, hypertensive, or idiopathic. Accurate diagnostic characterization of DCM is of foremost importance in order to guide tailored treatment for patients affected by this condition. CMR is an important noninvasive imaging tool that helps to characterize the etiology of DCM. This is achieved by evaluating the presence and distribution of macroscopic myocardial fibrosis with LGE sequences (Fig. 8.3 differential diagnosis). In particular, LGE is usually found in patients with LV dysfunction secondary to coronary artery disease. The pattern of distribution follows coronary perfusion territories, and the scar may be subendocardial or transmural. In patients presenting with de novo acute heart failure (HF) and no clinical or electrocardiographic suggestion of ischemic etiology, LGE-CMR is sensitive and specific for the presence of underlying significant coronary artery disease (CAD) [11, 12]. Conversely, LGE is absent in most patients with left ventricular dysfunction of nonischemic origin. If present in DCM, LGE is typically found in a mid-wall distribution without an apparent correlation to coronary perfusion territories [13, 14] (Fig. 8.4). Mid-wall LGE was found in 10-28\% of patients with DCM [13, 15]. Coexistent subendocardial LGE may indicate ischemic contribution to HF etiology despite the absence of angina and significant stenoses on coronary angiography, as infarction may follow coronary spasm or embolism, followed by spontaneous coronary recanalization $[13,16,17]$.

\subsection{Myocarditis Presenting as Left Ventricular Dysfunction}

Patients presenting with HF and LV dysfunction with or without dilatation may be affected by active myocarditis. Inflammatory processes are characterized by increased water content due to edema. CMR may show edema at T2-weighted sequences such as short tau inversion recovery (STIR), diffuse hyperemia at global relative enhancement (GRE) sequences or T1-weighted sequences early after gadolinium administration, or LGE with a myocarditic pattern (patchy subepicardial and/or mid-wall) (Fig. 8.5). Finding at least two of the aforementioned three criteria, the Lake Louise criteria (LLC) was found to have good diagnostic accuracy in identifying myocarditis presenting with chest pain and troponin release [18]. However, the sensitivity of the LLC criteria is greatest for patients with infarct-like rather than HF or arrhythmic presentations [19, 20].

Recently, T2-mapping sequences were designed to obtain a T2 signal intensity decay curve of the myocardium, in order to estimate myocardial T2 value and generate a color T2 map off-line (Fig. 8.6). Normal native T2 time ranges between 39 and $59 \mathrm{~ms}$. T2 relaxation time is increased in conditions characterized by myocardial edema [21]. In a recent study, patients with recent-onset HF and clinically suspected myocarditis revealed higher median global myocardial T2 values in those 

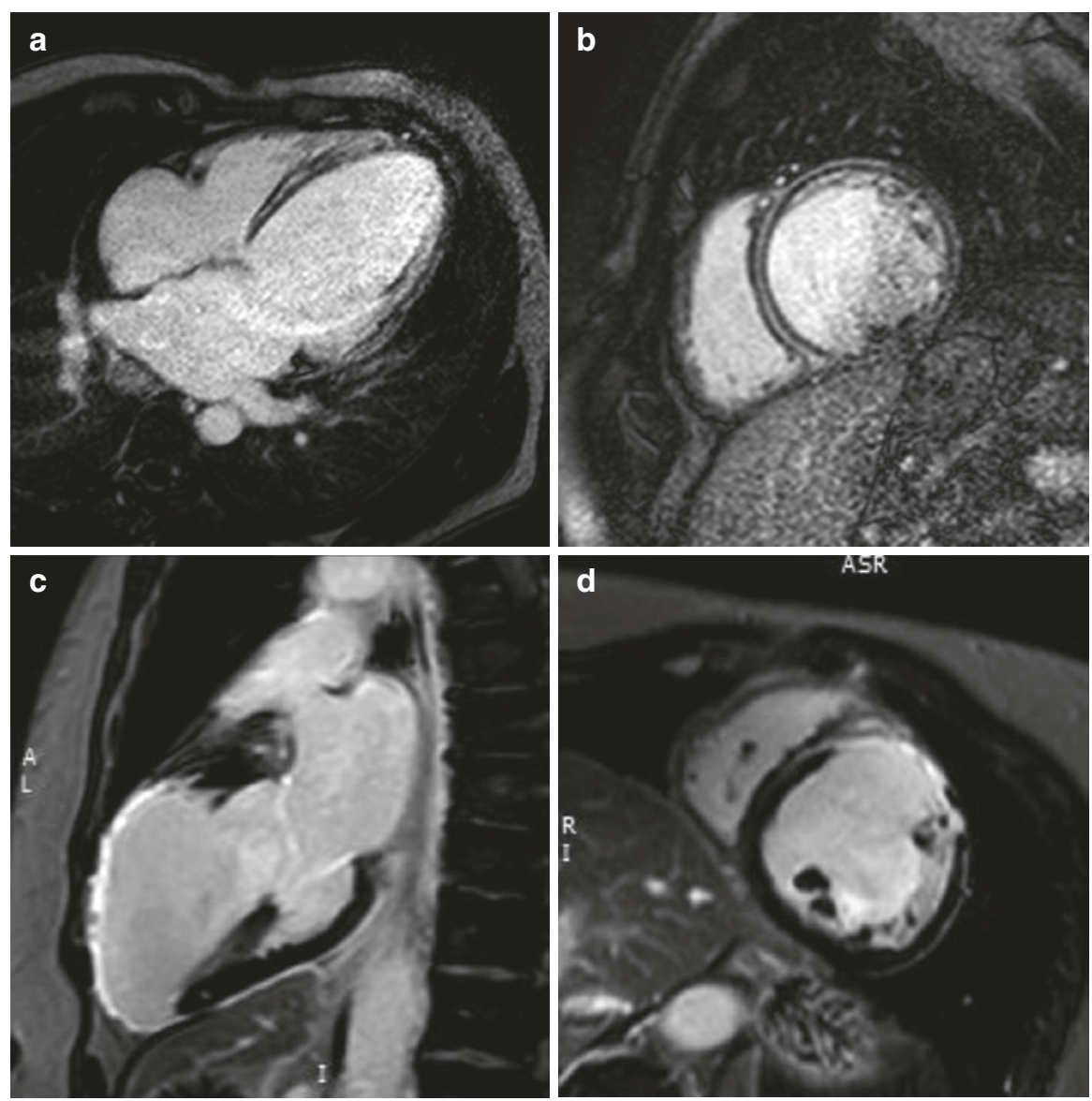

Fig. 8.4 Late gadolinium enhancement imaging in a case of DCM in four-chamber (a) and shortaxis (b) views showing patchy distribution of LGE (septal intramural and subepicardial free wall). LGE imaging in a case of LV dysfunction secondary to prior anterior myocardial infarction in two-chamber (c) and short-axis (d) views, showing transmural LGE in the left anterior descending territory

with biopsy-proven active myocarditis at T2 mapping, while there were no significant differences in native or post-contrast global myocardial T1 [22]. Caution must be applied when interpreting these results as T2 values may differ according to sequences and field strength [23, 24]. Furthermore, increased T2 values may be found in DCM patients without inflammation. Finally, differences between normal and pathological subjects can be very subtle and reported in the range of 10-20 ms, sometimes even overlapping normal T2 values, making it therefore difficult to define precise cutoff values [23, 25]. Nevertheless, despite these limitations T2 mapping can overcome the T2 or STIR sequence artifacts and is the only mapping sequence that allows for discrimination between inflammatory and noninflammatory cardiomyopathies [26]. 

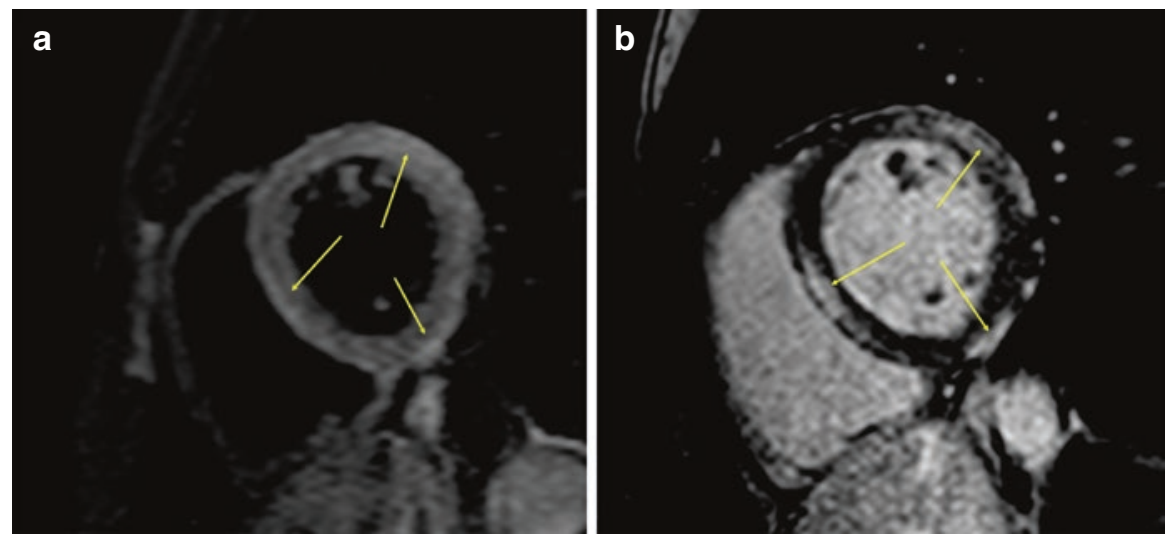

Fig. 8.5 CMR imaging in a patient with acute myocarditis: short-axis T2-weighted images (a) show edema, and short-axis LGE images (b) show patchy subepicardial LGE in the septum, inferior and anterolateral walls
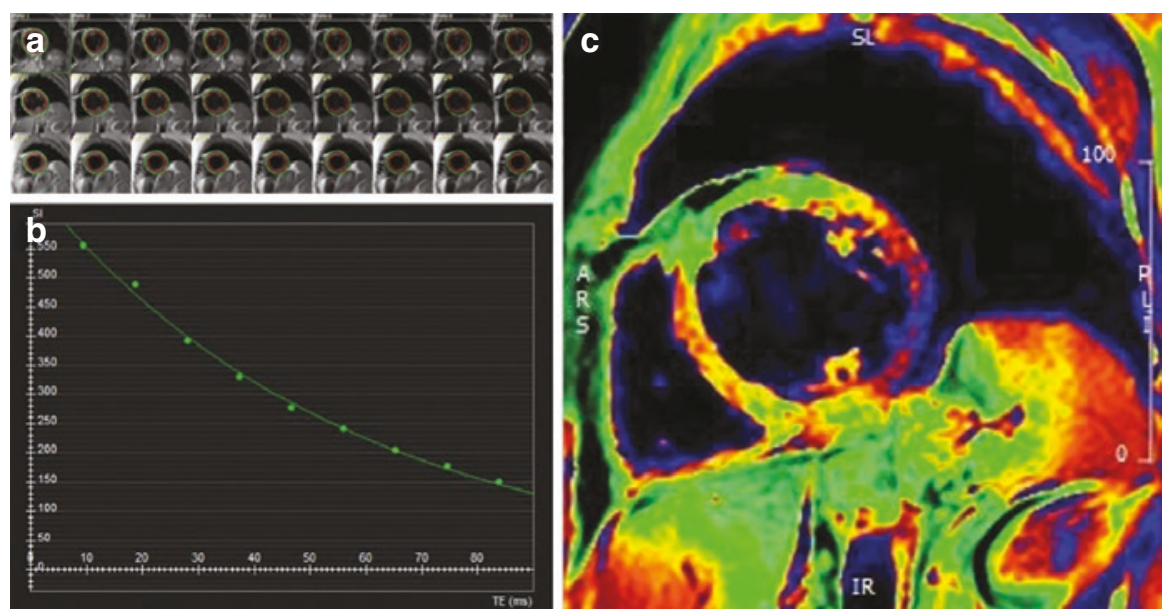

Fig. 8.6 T2 mapping with multi-echo spin-echo sequence: endocardial and epicardial contours are traced in all slices for each echo time (a). A T2 decay curve fit is obtained, and the T2 value is calculated for the region of interest (b). Results can also be depicted in color-coded maps (c)

As native $\mathrm{T} 1$ values increase with increasing myocardial water content, native $\mathrm{T} 1$ mapping may serve as a complementary technique to T2-weighted imaging for assessing myocardial edema in myocarditis presenting as infarct-like syndrome [22, 27] or where gadolinium is contraindicated. However, since native $\mathrm{T} 1$ values increase both with water content and with diffuse fibrosis, it is not able to discriminate between inflammatory and noninflammatory cardiomyopathies in patients presenting with heart failure [28]. 


\subsection{Other Secondary Forms of DCM}

CMR may help in diagnosing Chagas cardiomyopathy, caused by Trypanosoma cruzi infection, which results in LV dysfunction, HF, and ventricular arrhythmias. Its typical pattern is characterized by DCM with aneurysm formation with preferential sites at the apex and infero-lateral walls, which can be easily detected with SSFP cine imaging. The pattern of LGE is variable and may involve any or all layers of the myocardial wall $[29,30]$. CMR was also found to identify the early stages of the disease [29].

Cardiac involvement of sarcoidosis may manifest itself as LV dilatation and dysfunction. Patients with sarcoidosis develop large areas of LGE with variable distribution, which can precede the occurrence of LV dilatation, frequently involving the mid-wall of the basal septum, basal and lateral segments of the LV, and papillary muscles, unrelated to vascular territories [31].

\subsection{Prognostic Stratification}

Risk stratification is of foremost importance in DCM, particularly regarding the risk of sudden arrhythmic cardiac death (SCD). LV ejection fraction (LVEF) is the strongest predictor of progression to HF [32], while LV volume and mass are independently correlated with mortality and morbidity. Therefore, accurate quantification of all these parameters is essential to adequately evaluate patients and to monitor progression of disease and response to different therapeutic agents [33]. LVEF is the main criterion to select patients for primary prevention of SCD with implantable cardioverter-defibrillator (ICD) [34-36]. However, LVEF has low sensitivity and low specificity for the prediction of SCD [34, 37]. The use of low LVEF alone as an indicator for ICD placement is associated with both a low event rate of SCD in the control and treatment groups and a significant number of inappropriate ICD shocks [38]. Risk stratification for SCD among patients with nonischemic cardiomyopathy remains inadequate, causing ongoing clinical challenges in the appropriate identification of candidates for primary prevention ICDs [39].

In DCM, the remodeling process is characterized by changes in the extracellular matrix and interstitial fibrosis. The fibrous tissue constitutes a substrate for ventricular arrhythmias by inducing slow and heterogeneous conduction, favoring reentrant circuits, and producing vulnerability to life-threatening ventricular tachyarrhythmias [40]. Areas of LGE detected by CMR correlate well with histologically detected regional myocardial fibrosis in animal models and human explanted hearts $[41,42]$.

Several studies demonstrated that LGE is associated with an increased risk of adverse remodeling, hospitalization for $\mathrm{HF}$, ventricular arrhythmia induction, and SCD in patients with DCM [43-52]. A recent meta-analysis showed that LGE was present in a considerable proportion of patients with DCM (44\%), and 
it had a strong and significant association with the risk for ventricular arrhythmias and SCD. This association was consistently observed in patients at different stages of their cardiomyopathy and was independent of LVEF [53]. In DCM patients undergoing ICD placement for primary prevention of SCD, the presence of myocardial fibrosis is also predictive of appropriate device therapy [46, 54] regardless of LVEF. Mid-wall LGE may also identify a subgroup at high risk of SCD despite mild or moderate LV systolic impairment, not meeting conventional criteria for ICD implantation [55, 56]. Moreover, LGE extent is also associated with adverse outcomes [44]. However, LGE extent is variably described in studies, and there is no current consensus on the best method of LGE quantification [50]. A relationship between patterns of myocardial scar and arrhythmogenesis was also suggested: a scar with a transmurality of $26-75 \%$ is predictive of inducible ventricular tachycardia [43]. The detailed characterization of the heterogeneous boundary zone surrounding the LGE-CMR base scar has been linked to all-cause mortality and the most frequent ventricular arrhythmias although its role in DCM patients is still controversial [57]. Despite the abovementioned strong evidences, however, current guidelines from European Society of Cardiology [35] and more recently from American College of Cardiology/ American Heart Association/Heart Rhythm Society [36] do not mention arrhythmic risk stratification with LGE-CMR.

The presence and extent of LGE in patients with DCM also predicts a lack of improvement in LV function despite optimal medical treatment compared to a significant improvement in patients without LGE [48, 58-61]. Furthermore, LGE detected at CMR correlates with LV diastolic function evaluated by Doppler echocardiography. Patients with DCM and positive LGE have indices of higher diastolic filling pressure [62-64]. The presence and extent of LGE also correlates with echocardiographic measures of LV systolic dyssynchrony, an indicator of poor clinical outcome [65].

Scar burden was also found to be predictive of poor response to cardiac resynchronization therapy (CRT) [66]. Specifically, pacing over scar was associated with a higher risk of cardiac mortality or HF hospitalizations compared with pacing viable myocardium $[67,68]$. Moreover, pacing a transmural scar was associated with a worse outcome than pacing a subendocardial scar [69]. Scar in the vicinity of right ventricular (RV) lead during CRT may also be associated with suboptimal left ventricular reverse remodeling (LVRR) [70]. However, the strategy avoiding myocardial scar in lead implantation has not been evaluated by multicenter, randomized, controlled trials.

\subsection{Macroscopic vs. Diffuse Fibrosis}

Myocardial scar is the main substrate for ventricular arrhythmias, but not all patients with DCM have identifiable scars, especially in cases of diffuse fibrosis. In most patients with DCM, myocardial fibrosis does not progress focally but instead 
gradually and randomly, leading to irreversible replacement fibrosis [42, 71]. LGE sequences are designed to improve signal contrast differences between zones of normal myocardium and zones with focal fibrosis or necrosis [72, 73]. The technique is however very limited in the quantification of widespread tissue fibrosis $[72,74,75]$. This impairment has been nowadays overcome with the introduction of another family of sequences (MOLLI, Sh-MOLLI, SASHA, and SAPPHIRE) that are able to quantitatively identify real myocardial $\mathrm{T} 1$ recovery time, native and post-contrast, and to quantify extracellular volume (ECV). It is also possible to assess all the collected data in color maps (Fig. 8.7) [76-78]. T1-mapping techniques correlate with myocardial histology [79-82] and may allow the early differentiation of diseased myocardium from healthy myocardium, in the absence of LGE [80, 83]. Native T1 and ECV are increased, and post-contrast T1 is decreased in nonischemic DCM patients [81, 83, 84]. All T1-mapping measures have been linked to prognosis in nonischemic DCM patients [85-88]. However, native T1 was found to be the sole independent predictor of all-cause and HF composite endpoints in a recent large prospective multicenter observational study [86]. Native $\mathrm{T} 1$ has also shown a strong relationship with markers of structural and functional LV remodeling, diastolic impairment, and the severity of functional mitral regurgitation [89-91].
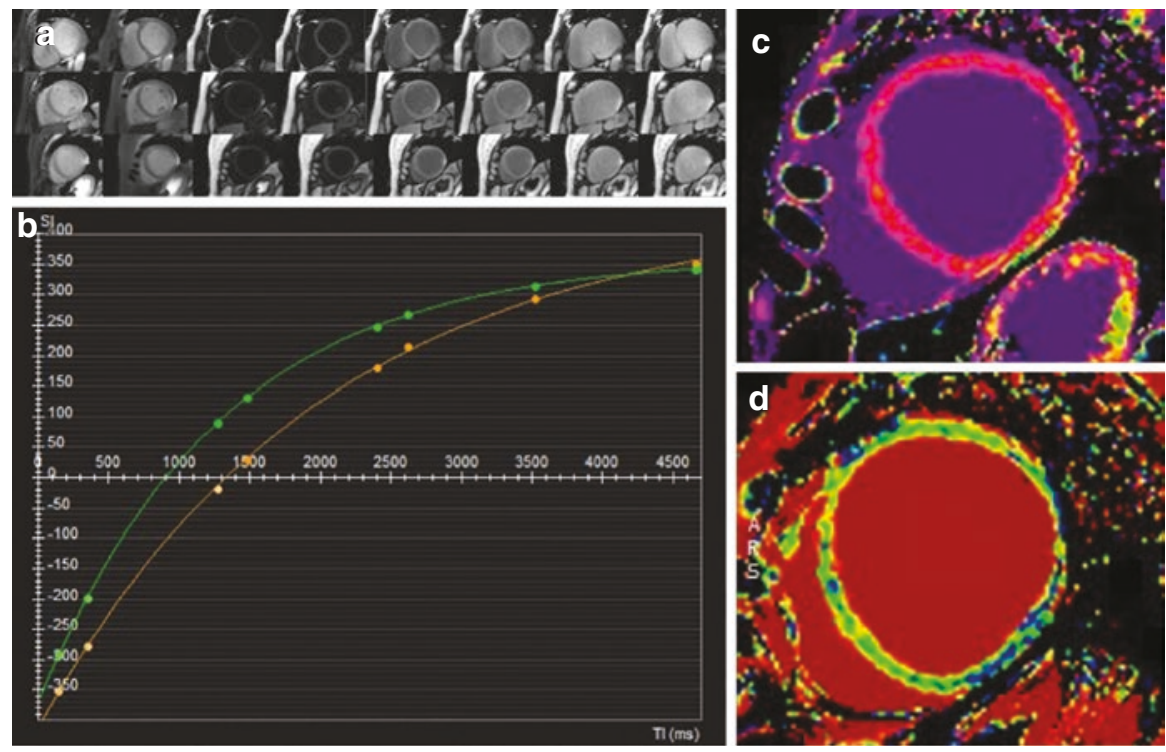

Fig. 8.7 T1 mapping with modified look-locker sequence: inversion recovery images with different inversion times are obtained (a) in short-axis views, before (native) and after (contrastenhanced) gadolinium administration. The signal intensity is measured in each image, and a T1 relaxation curve (b) is obtained for the myocardium (green) and blood (orange). Results can be depicted as color-coded maps of native myocardial T1 (c) and ECV (d) 


\subsection{Strain Analysis}

In DCM, the occurrence of nonhomogeneous fibrous substitution of cardiomyocytes may alter mechanical activity in these areas [92], thus leading to a heterogeneous compromise of regional contractile function [93]. Myocardial deformation analysis can supply useful information for the evaluation of global and regional myocardial function $[94,95]$. CMR tagging is considered a reference standard for the assessment of myocardial regional function [96]. By adding grids or lines to the imaging plane through selective saturation pulses, and following them throughout the cardiac cycle, myocardial deformation can be quantitatively analyzed. However, the need for additional acquisition sequences and time-consuming protocols have limited its clinical application. Recently, new CMR feature tracking technology, which agrees well with CMR tagging, has allowed for the assessment of global and regional myocardial strain by tracking patterns of features or irregularities comprised between the endocardial and epicardial borders during cardiac cycle using SSFP long-axis and short-axis cine images (Fig. 8.8). This technology, similar to speckle tracking, can be applied to routine cine-CMR acquisitions, thus avoiding the need for dedicated pulse sequences [97]. Global longitudinal, circumferential, and radial strain are significantly impaired in patients with DCM [98]. More importantly, there is growing evidence that CMR-derived strain analysis is a predictor of adverse events in patients with nonischemic DCM [99-101]. In particular, global longitudinal strain analysis has independent and incremental prognostic value to
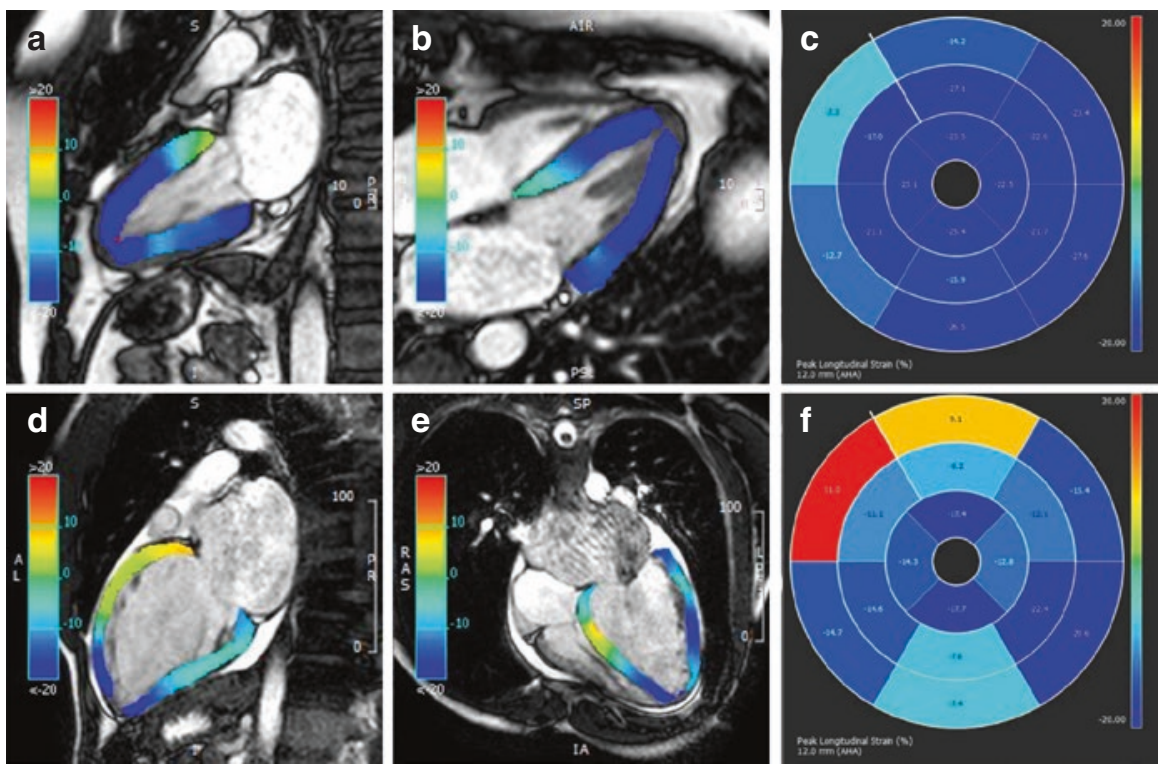

Fig. 8.8 Strain analysis in a normal subject (a-c) and in a patient with DCM (d-f) at 1.5T. Colorcoded maps of peak longitudinal strain in two-chamber $(\mathbf{a}, \mathbf{d})$ and four-chamber $(\mathbf{b}, \mathbf{e})$ views. Bull's-eye graphic depicting peak longitudinal strain values in all AHA segments (c, f) 
other risk factors including LVEF, LGE, and ECV [99-103]. Peak circumferential strain in association with the absence of LGE and LV mass were found to be predictive of LVRR [104].

Cardiac dyssynchrony assessed by CMR strain analysis, associated with LGE imaging, was also suggested to better predict improvement in functional class after CRT implantation [105], compared to currently recommended parameters for patient selection [106].

\subsection{Other Prognostic Indicators}

Biventricular involvement in DCM identifies a subset of patients with poor outcome [107, 108]. CMR is considered the gold standard for noninvasive assessment of RV function $[7,8]$. RV ejection fraction (RVEF) $\leq 45 \%$ was shown to be independently associated with adverse outcome in nonischemic DCM patients [109]. Furthermore, $\mathrm{RV}$ longitudinal strain is also an independent predictor of outcome and offers additional prognostic information over RVEF [110].

Left atrial enlargement is associated with adverse outcome in patients with DCM $[111,112]$. Left atrial volume (LAV) provides the most accurate estimate of left atrial size compared to linear dimension in M-mode and area in 2D echocardiography [113]. Echocardiographic measures systematically underestimate LAV compared to CMR [6], even though both methods are reproducible and have limited intra- or interobserver variability. A LAV index $>72 \mathrm{~mL} / \mathrm{m}^{2}$, measured with the biplane arealength method, was found to be an independent predictor of adverse events in DCM [114]. Conversely, LAV index $<38 \mathrm{~mL} / \mathrm{m}^{2}$ is predictive of LVRR [115].

Finally, RV dysfunction [109], but not greater degrees of trabeculation [116], is an independent predictor of survival and HF outcomes in patients with DCM.

\subsection{Computed Tomography}

Cardiac computed tomography (CCT) is a noninvasive cardiac imaging technique that is increasingly gaining importance in DCM patients. It is mainly used to test for the presence of CAD but may also play a role in the evaluation of cardiac volumes and function, characterization of the type of cardiomyopathy, and treatment planning.

Calcium score may be useful in excluding CAD as the etiology for HF. In patients with HF, an Agatston score of 0 has been shown to have $100 \%$ specificity in excluding left main or $\geq 2$-vessel coronary artery disease [117, 118]. Computed tomography coronary angiography (CTCA) (Fig. 8.9) is a highly accurate diagnostic modality for excluding CAD in patients with DCM of undetermined cause [119122], especially in the low- to intermediate-risk population due to its high specificity (95-98\%) and negative predictive value (95-100\%) [123-125].

Prospective ECG triggering is the preferred CTCA mode to minimize radiation dose, although this is possible only if the heart rate is slow and regular. Retrospective 

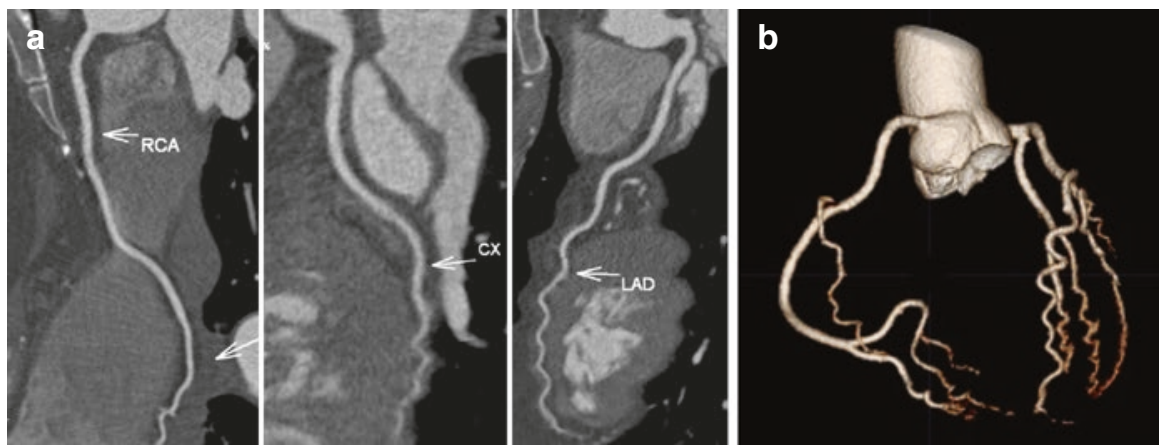

Fig. 8.9 Curved multiplanar reconstructions (cMPR) of the right coronary (RCA), left circumflex (CX), and left anterior descending (LAD) arteries obtained from a coronary CTA in a patient with normal coronary arteries (a). Three-dimensional volume reconstruction (3DVR) is shown in panel (b)

ECG gating must be used if the heart rate is high or irregular. This mode is also used for the evaluation of cardiac function and volumes, wall motion, and valvular abnormalities, with good correlation with CMR and contrast-enhanced echocardiography [2, 126-129]. Latest technologies such as CT perfusion and CT-FFR may give additional important information on the hemodynamic significance of coronary artery disease [130-135].

There is increasing evidence supporting the usefulness of CCT for the detection of myocardial fibrosis in patients with hypertrophic cardiomyopathy [136] and after myocardial infarction $[137,138]$ through late iodine enhancement (LIE), although CMR remains more sensitive. However, data in DCM patients are still limited. Initial data suggest that LIE-CCT correlates well with LGE-CMR and electroanatomic mapping [139, 140]. LIE may also be used for ECV assessment [141]. It has good correlation with T1-mapping methods and is associated with increased LV volume and reduced EF and circumferential strain [142]. Dual-energy CT reduces imaging artifacts and increases contrast to noise ratio and thus may improve LIE images compared to conventional CT $[143,144]$.

A number of challenges still remain, relating to the required contrast dose, image quality, and radiation exposure. CTCA has been given a high appropriateness rating for the evaluation of ischemic etiology in patients presenting with $\operatorname{HF}[145,146]$. However, for all other indications, CCT should still be reserved for patients with contraindications or suboptimal results of other imaging tests.

\section{References}

1. Bellenger NG, Burgess MI, Ray SG, Lahiri A, Coats AJ, Cleland JG, et al. Comparison of left ventricular ejection fraction and volumes in heart failure by echocardiography, radionuclide ventriculography and cardiovascular magnetic resonance; are they interchangeable? Eur Heart J. 2000;21(16):1387-96.

2. Greupner J, Zimmermann E, Grohmann A, Dubel HP, Althoff TF, Borges AC, et al. Head-tohead comparison of left ventricular function assessment with 64-row computed tomography, 
biplane left cineventriculography, and both 2- and 3-dimensional transthoracic echocardiography: comparison with magnetic resonance imaging as the reference standard. J Am Coll Cardiol. 2012;59(21):1897-907.

3. Moon JC, Lorenz CH, Francis JM, Smith GC, Pennell DJ. Breath-hold FLASH and FISP cardiovascular MR imaging: left ventricular volume differences and reproducibility. Radiology. 2002;223(3):789-97.

4. Thuny F, Jacquier A, Jop B, Giorgi R, Gaubert JY, Bartoli JM, et al. Assessment of left ventricular non-compaction in adults: side-by-side comparison of cardiac magnetic resonance imaging with echocardiography. Arch Cardiovasc Dis. 2010;103(3):150-9.

5. Anderson JL, Horne BD, Pennell DJ. Atrial dimensions in health and left ventricular disease using cardiovascular magnetic resonance. J Cardiovasc Magn Reson. 2005;7(4):671-5.

6. Whitlock M, Garg A, Gelow J, Jacobson T, Broberg C. Comparison of left and right atrial volume by echocardiography versus cardiac magnetic resonance imaging using the area-length method. Am J Cardiol. 2010;106(9):1345-50.

7. Grothues F, Moon JC, Bellenger NG, Smith GS, Klein HU, Pennell DJ. Interstudy reproducibility of right ventricular volumes, function, and mass with cardiovascular magnetic resonance. Am Heart J. 2004;147(2):218-23.

8. Mooij CF, de Wit CJ, Graham DA, Powell AJ, Geva T. Reproducibility of MRI measurements of right ventricular size and function in patients with normal and dilated ventricles. J Magn Reson Imaging. 2008;28(1):67-73.

9. Roifman I, Connelly KA, Wright GA, Wijeysundera HC. Echocardiography vs. cardiac magnetic resonance imaging for the diagnosis of left ventricular thrombus: a systematic review. Can J Cardiol. 2015;31(6):785-91.

10. Goyal P, Weinsaft JW. Cardiovascular magnetic resonance imaging for assessment of cardiac thrombus. Methodist Debakey Cardiovasc J. 2013;9(3):132-6.

11. Casolo G, Minneci S, Manta R, Sulla A, Del Meglio J, Rega L, et al. Identification of the ischemic etiology of heart failure by cardiovascular magnetic resonance imaging: diagnostic accuracy of late gadolinium enhancement. Am Heart J. 2006;151(1):101-8.

12. Valle-Munoz A, Estornell-Erill J, Soriano-Navarro CJ, Nadal-Barange M, MartinezAlzamora N, Pomar-Domingo F, et al. Late gadolinium enhancement-cardiovascular magnetic resonance identifies coronary artery disease as the aetiology of left ventricular dysfunction in acute new-onset congestive heart failure. Eur $\mathrm{J}$ Echocardiogr. 2009;10(8):968-74.

13. McCrohon JA, Moon JC, Prasad SK, McKenna WJ, Lorenz CH, Coats AJ, et al. Differentiation of heart failure related to dilated cardiomyopathy and coronary artery disease using gadolinium-enhanced cardiovascular magnetic resonance. Circulation. 2003;108(1):54-9.

14. Mahrholdt H, Wagner A, Deluigi CC, Kispert E, Hager S, Meinhardt G, et al. Presentation, patterns of myocardial damage, and clinical course of viral myocarditis. Circulation. 2006;114(15):1581-90.

15. Soriano CJ, Ridocci F, Estornell J, Jimenez J, Martinez V, De Velasco JA. Noninvasive diagnosis of coronary artery disease in patients with heart failure and systolic dysfunction of uncertain etiology, using late gadolinium-enhanced cardiovascular magnetic resonance. J Am Coll Cardiol. 2005;45(5):743-8.

16. Bello D, Shah DJ, Farah GM, Di Luzio S, Parker M, Johnson MR, et al. Gadolinium cardiovascular magnetic resonance predicts reversible myocardial dysfunction and remodeling in patients with heart failure undergoing beta-blocker therapy. Circulation. 2003;108(16):1945-53.

17. Karamitsos TD, Francis JM, Myerson S, Selvanayagam JB, Neubauer S. The role of cardiovascular magnetic resonance imaging in heart failure. J Am Coll Cardiol. 2009;54(15):1407-24.

18. Friedrich MG, Sechtem U, Schulz-Menger J, Holmvang G, Alakija P, Cooper LT, et al. Cardiovascular magnetic resonance in myocarditis: a JACC White Paper. J Am Coll Cardiol. 2009;53(17):1475-87.

19. Gutberlet M, Spors B, Thoma T, Bertram H, Denecke T, Felix R, et al. Suspected chronic myocarditis at cardiac MR: diagnostic accuracy and association with immunohistologically detected inflammation and viral persistence. Radiology. 2008;246(2):401-9. 
20. Francone M, Chimenti C, Galea N, Scopelliti F, Verardo R, Galea R, et al. CMR sensitivity varies with clinical presentation and extent of cell necrosis in biopsy-proven acute myocarditis. J Am Coll Cardiol Img. 2014;7(3):254-63.

21. Kim PK, Hong YJ, Im DJ, Suh YJ, Park CH, Kim JY, et al. Myocardial T1 and T2 mapping: techniques and clinical applications. Korean J Radiol. 2017;18(1):113-31.

22. Lurz P, Luecke C, Eitel I, Fohrenbach F, Frank C, Grothoff M, et al. Comprehensive cardiac magnetic resonance imaging in patients with suspected myocarditis: the myoracer-trial. J Am Coll Cardiol. 2016;67(15):1800-11.

23. Wassmuth R, Prothmann M, Utz W, Dieringer M, von Knobelsdorff-Brenkenhoff F, Greiser A, et al. Variability and homogeneity of cardiovascular magnetic resonance myocardial T2-mapping in volunteers compared to patients with edema. J Cardiovasc Magn Reson. 2013;15:27.

24. Baessler B, Schaarschmidt F, Stehning C, Schnackenburg B, Maintz D, Bunck AC. Cardiac T2-mapping using a fast gradient echo spin echo sequence - first in vitro and in vivo experience. J Cardiovasc Magn Reson. 2015;17:67.

25. Thavendiranathan P, Walls M, Giri S, Verhaert D, Rajagopalan S, Moore S, et al. Improved detection of myocardial involvement in acute inflammatory cardiomyopathies using T2 mapping. Circ Cardiovasc Imaging. 2012;5(1):102-10.

26. Verhaert D, Thavendiranathan P, Giri S, Mihai G, Rajagopalan S, Simonetti OP, et al. Direct T2 quantification of myocardial edema in acute ischemic injury. JACC Cardiovasc Imaging. 2011;4(3):269-78.

27. Ferreira VM, Piechnik SK, Dall'Armellina E, Karamitsos TD, Francis JM, Choudhury RP, et al. Non-contrast T1-mapping detects acute myocardial edema with high diagnostic accuracy: a comparison to T2-weighted cardiovascular magnetic resonance. J Cardiovasc Magn Reson. 2012;14:42.

28. Bohnen S, Radunski UK, Lund GK, Kandolf R, Stehning C, Schnackenburg B, et al. Performance of $\mathrm{t} 1$ and $\mathrm{t} 2$ mapping cardiovascular magnetic resonance to detect active myocarditis in patients with recent-onset heart failure. Circ Cardiovasc Imaging. 2015;8(6). pii: e003073.

29. Rochitte CE, Oliveira PF, Andrade JM, Ianni BM, Parga JR, Avila LF, et al. Myocardial delayed enhancement by magnetic resonance imaging in patients with Chagas' disease: a marker of disease severity. J Am Coll Cardiol. 2005;46(8):1553-8.

30. Regueiro A, Garcia-Alvarez A, Sitges M, Ortiz-Perez JT, De Caralt MT, Pinazo MJ, et al. Myocardial involvement in Chagas disease: insights from cardiac magnetic resonance. Int $\mathrm{J}$ Cardiol. 2013;165(1):107-12.

31. Schatka I, Bengel FM. Advanced imaging of cardiac sarcoidosis. J Nucl Med. 2014;55(1):99-106.

32. Grzybowski J, Bilinska ZT, Ruzyllo W, Kupsc W, Michalak E, Szczesniewska D, et al. Determinants of prognosis in nonischemic dilated cardiomyopathy. J Card Fail. 1996;2(2):77-85.

33. Lehrke S, Lossnitzer D, Schob M, Steen H, Merten C, Kemmling H, et al. Use of cardiovascular magnetic resonance for risk stratification in chronic heart failure: prognostic value of late gadolinium enhancement in patients with non-ischaemic dilated cardiomyopathy. Heart. 2011;97(9):727-32.

34. Buxton AE, Lee KL, Hafley GE, Pires LA, Fisher JD, Gold MR, et al. Limitations of ejection fraction for prediction of sudden death risk in patients with coronary artery disease: lessons from the MUSTT study. J Am Coll Cardiol. 2007;50(12):1150-7.

35. Priori SG, Blomstrom-Lundqvist C, Mazzanti A, Blom N, Borggrefe M, Camm J, et al. 2015 ESC Guidelines for the management of patients with ventricular arrhythmias and the prevention of sudden cardiac death: The Task Force for the Management of Patients with Ventricular Arrhythmias and the Prevention of Sudden Cardiac Death of the European Society of Cardiology (ESC). Endorsed by: Association for European Paediatric and Congenital Cardiology (AEPC). Eur Heart J. 2015;36(41):2793-867. 
36. Al-Khatib SM, Stevenson WG, Ackerman MJ, Bryant WJ, Callans DJ, Curtis AB, et al. AHA/ACC/HRS Guideline for management of patients with ventricular arrhythmias and the prevention of sudden cardiac death: executive summary: a report of the American College of Cardiology/American Heart Association Task Force on Clinical Practice Guidelines and the Heart Rhythm Society. Circulation. 2017, 2017; https://doi.org/10.1161/ CIR.0000000000000548.

37. Kober L, Thune JJ, Nielsen JC, Haarbo J, Videbaek L, Korup E, et al. Defibrillator implantation in patients with nonischemic systolic heart failure. N Engl J Med. 2016;375(13):1221-30.

38. Kadish A, Dyer A, Daubert JP, Quigg R, Estes NA, Anderson KP, et al. Prophylactic defibrillator implantation in patients with nonischemic dilated cardiomyopathy. N Engl J Med. 2004;350(21):2151-8.

39. Arbustini E, Disertori M, Narula J. Primary prevention of sudden arrhythmic death in dilated cardiomyopathy: current guidelines and risk stratification. JACC Heart Fail. 2017;5(1):39-43.

40. Pogwizd SM, McKenzie JP, Cain ME. Mechanisms underlying spontaneous and induced ventricular arrhythmias in patients with idiopathic dilated cardiomyopathy. Circulation. 1998;98(22):2404-14.

41. Kim RJ, Fieno DS, Parrish TB, Harris K, Chen EL, Simonetti O, et al. Relationship of MRI delayed contrast enhancement to irreversible injury, infarct age, and contractile function. Circulation. 1999;100(19):1992-2002.

42. Iles LM, Ellims AH, Llewellyn H, Hare JL, Kaye DM, McLean CA, et al. Histological validation of cardiac magnetic resonance analysis of regional and diffuse interstitial myocardial fibrosis. Eur Heart J Cardiovasc Imaging. 2015;16(1):14-22.

43. Nazarian S, Bluemke DA, Lardo AC, Zviman MM, Watkins SP, Dickfeld TL, et al. Magnetic resonance assessment of the substrate for inducible ventricular tachycardia in nonischemic cardiomyopathy. Circulation. 2005;112(18):2821-5.

44. Assomull RG, Prasad SK, Lyne J, Smith G, Burman ED, Khan M, et al. Cardiovascular magnetic resonance, fibrosis, and prognosis in dilated cardiomyopathy. J Am Coll Cardiol. 2006;48(10): 1977-85.

45. Wu KC, Weiss RG, Thiemann DR, Kitagawa K, Schmidt A, Dalal D, et al. Late gadolinium enhancement by cardiovascular magnetic resonance heralds an adverse prognosis in nonischemic cardiomyopathy. J Am Coll Cardiol. 2008;51(25):2414-21.

46. Klem I, Weinsaft JW, Bahnson TD, Hegland D, Kim HW, Hayes B, et al. Assessment of myocardial scarring improves risk stratification in patients evaluated for cardiac defibrillator implantation. J Am Coll Cardiol. 2012;60(5):408-20.

47. Gulati A, Jabbour A, Ismail TF, Guha K, Khwaja J, Raza S, et al. Association of fibrosis with mortality and sudden cardiac death in patients with nonischemic dilated cardiomyopathy. JAMA. 2013;309(9):896-908.

48. Kubanek M, Sramko M, Maluskova J, Kautznerova D, Weichet J, Lupinek P, et al. Novel predictors of left ventricular reverse remodeling in individuals with recent-onset dilated cardiomyopathy. J Am Coll Cardiol. 2013;61(1):54-63.

49. Neilan TG, Coelho-Filho OR, Danik SB, Shah RV, Dodson JA, Verdini DJ, et al. CMR quantification of myocardial scar provides additive prognostic information in nonischemic cardiomyopathy. JACC Cardiovasc Imaging. 2013;6(9):944-54.

50. Kuruvilla S, Adenaw N, Katwal AB, Lipinski MJ, Kramer CM, Salerno M. Late gadolinium enhancement on cardiac magnetic resonance predicts adverse cardiovascular outcomes in nonischemic cardiomyopathy: a systematic review and meta-analysis. Circ Cardiovasc Imaging. 2014;7(2):250-8.

51. Perazzolo Marra M, De Lazzari M, Zorzi A, Migliore F, Zilio F, Calore C, et al. Impact of the presence and amount of myocardial fibrosis by cardiac magnetic resonance on arrhythmic outcome and sudden cardiac death in nonischemic dilated cardiomyopathy. Heart Rhythm. 2014;11(5):856-63.

52. Disertori M, Rigoni M, Pace N, Casolo G, Mase M, Gonzini L, et al. Myocardial fibrosis assessment by LGE is a powerful predictor of ventricular tachyarrhythmias in isch- 
emic and nonischemic LV dysfunction: a meta-analysis. JACC Cardiovasc Imaging. 2016;9(9):1046-55.

53. Di Marco A, Anguera I, Schmitt M, Klem I, Neilan TG, White JA, et al. Late gadolinium enhancement and the risk for ventricular arrhythmias or sudden death in dilated cardiomyopathy: systematic review and meta-analysis. JACC Heart Fail. 2017;5(1):28-38.

54. Iles L, Pfluger H, Lefkovits L, Butler MJ, Kistler PM, Kaye DM, et al. Myocardial fibrosis predicts appropriate device therapy in patients with implantable cardioverter-defibrillators for primary prevention of sudden cardiac death. J Am Coll Cardiol. 2011;57(7):821-8.

55. Venero JV, Doyle M, Shah M, Rathi VK, Yamrozik JA, Williams RB, et al. Mid wall fibrosis on CMR with late gadolinium enhancement may predict prognosis for LVAD and transplantation risk in patients with newly diagnosed dilated cardiomyopathy-preliminary observations from a high-volume transplant centre. ESC Heart Fail. 2015;2(4):150-9.

56. Halliday BP, Gulati A, Ali A, Guha K, Newsome S, Arzanauskaite M, et al. Association between midwall late gadolinium enhancement and sudden cardiac death in patients with dilated cardiomyopathy and mild and moderate left ventricular systolic dysfunction. Circulation. 2017;135(22):2106-15.

57. Jablonowski R, Chaudhry U, van der Pals J, Engblom H, Arheden H, Heiberg E, et al. Cardiovascular magnetic resonance to predict appropriate implantable cardioverter defibrillator therapy in ischemic and nonischemic cardiomyopathy patients using late gadolinium enhancement border zone: comparison of four analysis methods. Circ Cardiovasc Imaging. 2017;10(9). pii: e006105.

58. Park S, Choi BW, Rim SJ, Shim CY, Ko YG, Kang SM, et al. Delayed hyperenhancement magnetic resonance imaging is useful in predicting functional recovery of nonischemic left ventricular systolic dysfunction. J Card Fail. 2006;12(2):93-9.

59. Leong DP, Chakrabarty A, Shipp N, Molaee P, Madsen PL, Joerg L, et al. Effects of myocardial fibrosis and ventricular dyssynchrony on response to therapy in new-presentation idiopathic dilated cardiomyopathy: insights from cardiovascular magnetic resonance and echocardiography. Eur Heart J. 2012;33(5):640-8.

60. Ikeda Y, Inomata T, Fujita T, Iida Y, Nabeta T, Ishii S, et al. Cardiac fibrosis detected by magnetic resonance imaging on predicting time course diversity of left ventricular reverse remodeling in patients with idiopathic dilated cardiomyopathy. Heart Vessels. 2016;31(11):1817-25.

61. Yingchoncharoen T, Jellis C, Popovic ZB, Wang L, Gai N, Levy WC, et al. Focal fibrosis and diffuse fibrosis are predictors of reversed left ventricular remodeling in patients with nonischemic cardiomyopathy. Int J Cardiol. 2016;221:498-504.

62. Choi EY, Choi BW, Kim SA, Rhee SJ, Shim CY, Kim YJ, et al. Patterns of late gadolinium enhancement are associated with ventricular stiffness in patients with advanced nonischaemic dilated cardiomyopathy. Eur J Heart Fail. 2009;11(6):573-80.

63. Nanjo S, Yoshikawa K, Harada M, Inoue Y, Namiki A, Nakano H, et al. Correlation between left ventricular diastolic function and ejection fraction in dilated cardiomyopathy using magnetic resonance imaging with late gadolinium enhancement. Circ J. 2009;73(10):1939-44.

64. Malaty AN, Shah DJ, Abdelkarim AR, Nagueh SF. Relation of replacement fibrosis to left ventricular diastolic function in patients with dilated cardiomyopathy. J Am Soc Echocardiogr. 2011;24(3):333-8.

65. Tigen K, Karaahmet T, Kirma C, Dundar C, Pala S, Isiklar I, et al. Diffuse late gadolinium enhancement by cardiovascular magnetic resonance predicts significant intraventricular systolic dyssynchrony in patients with non-ischemic dilated cardiomyopathy. J Am Soc Echocardiogr. 2010;23(4):416-22.

66. White JA, Yee R, Yuan X, Krahn A, Skanes A, Parker M, et al. Delayed enhancement magnetic resonance imaging predicts response to cardiac resynchronization therapy in patients with intraventricular dyssynchrony. J Am Coll Cardiol. 2006;48(10):1953-60.

67. Chalil S, Foley PW, Muyhaldeen SA, Patel KC, Yousef ZR, Smith RE, et al. Late gadolinium enhancement-cardiovascular magnetic resonance as a predictor of response to cardiac resynchronization therapy in patients with ischaemic cardiomyopathy. Europace. 2007;9(11):1031-7. 
68. Leyva F, Foley PW, Chalil S, Ratib K, Smith RE, Prinzen F, et al. Cardiac resynchronization therapy guided by late gadolinium-enhancement cardiovascular magnetic resonance. $\mathrm{J}$ Cardiovasc Magn Reson. 2011;13:29.

69. Chalil S, Stegemann B, Muhyaldeen SA, Khadjooi K, Foley PW, Smith RE, et al. Effect of posterolateral left ventricular scar on mortality and morbidity following cardiac resynchronization therapy. Pacing Clin Electrophysiol. 2007;30(10):1201-9.

70. Wong JA, Yee R, Stirrat J, Scholl D, Krahn AD, Gula LJ, et al. Influence of pacing site characteristics on response to cardiac resynchronization therapy. Circ Cardiovasc Imaging. 2013;6(4):542-50.

71. Brooks A, Schinde V, Bateman AC, Gallagher PJ. Interstitial fibrosis in the dilated nonischaemic myocardium. Heart. 2003;89(10):1255-6.

72. Jellis C, Martin J, Narula J, Marwick TH. Assessment of nonischemic myocardial fibrosis. J Am Coll Cardiol. 2010;56(2):89-97.

73. Mewton N, Liu CY, Croisille P, Bluemke D, Lima JA. Assessment of myocardial fibrosis with cardiovascular magnetic resonance. J Am Coll Cardiol. 2011;57(8):891-903.

74. Schalla S, Bekkers SC, Dennert R, van Suylen RJ, Waltenberger J, Leiner T, et al. Replacement and reactive myocardial fibrosis in idiopathic dilated cardiomyopathy: comparison of magnetic resonance imaging with right ventricular biopsy. Eur J Heart Fail. 2010;12(3):227-31.

75. Francone M. Role of cardiac magnetic resonance in the evaluation of dilated cardiomyopathy: diagnostic contribution and prognostic significance. ISRN Radiol. 2014;2014:365404.

76. Hamlin SA, Henry TS, Little BP, Lerakis S, Stillman AE. Mapping the future of cardiac MR imaging: case-based review of T1 and T2 mapping techniques. Radiographics. 2014;34(6):1594-611.

77. Haaf P, Garg P, Messroghli DR, Broadbent DA, Greenwood JP, Plein S. Cardiac T1 mapping and extracellular volume (ECV) in clinical practice: a comprehensive review. J Cardiovasc Magn Reson. 2016;18(1):89.

78. Salerno M, Sharif B, Arheden H, Kumar A, Axel L, Li D, et al. Recent advances in cardiovascular magnetic resonance: techniques and applications. Circ Cardiovasc Imaging. 2017;10(6). pii: e003951.

79. Sibley CT, Noureldin RA, Gai N, Nacif MS, Liu S, Turkbey EB, et al. T1 mapping in cardiomyopathy at cardiac MR: comparison with endomyocardial biopsy. Radiology. 2012;265(3):724-32.

80. aus dem Siepen F, Buss SJ, Messroghli D, Andre F, Lossnitzer D, Seitz S, et al. T1 mapping in dilated cardiomyopathy with cardiac magnetic resonance: quantification of diffuse myocardial fibrosis and comparison with endomyocardial biopsy. Eur Heart J Cardiovasc Imaging. 2015;16(2):210-6.

81. Inui K, Tachi M, Saito T, Kubota Y, Murai K, Kato K, et al. Superiority of the extracellular volume fraction over the myocardial $\mathrm{T} 1$ value for the assessment of myocardial fibrosis in patients with non-ischemic cardiomyopathy. Magn Reson Imaging. 2016;34(8):1141-5.

82. Nakamori S, Dohi K, Ishida M, Goto Y, Imanaka-Yoshida K, Omori T, et al. Native T1 mapping and extracellular volume mapping for the assessment of diffuse myocardial fibrosis in dilated cardiomyopathy. J Am Coll Cardiol Img. 2018;11(1):48-59.

83. Puntmann VO, Voigt T, Chen Z, Mayr M, Karim R, Rhode K, et al. Native T1 mapping in differentiation of normal myocardium from diffuse disease in hypertrophic and dilated cardiomyopathy. J Am Coll Cardiol Img. 2013;6(4):475-84.

84. Iles L, Pfluger H, Phrommintikul A, Cherayath J, Aksit P, Gupta SN, et al. Evaluation of diffuse myocardial fibrosis in heart failure with cardiac magnetic resonance contrast-enhanced T1 mapping. J Am Coll Cardiol. 2008;52(19):1574-80.

85. Kammerlander AA, Marzluf BA, Zotter-Tufaro C, Aschauer S, Duca F, Bachmann A, et al. T1 mapping by CMR imaging: from histological validation to clinical implication. JACC Cardiovasc Imaging. 2016;9(1):14-23.

86. Puntmann VO, Carr-White G, Jabbour A, Yu CY, Gebker R, Kelle S, et al. T1-mapping and outcome in nonischemic cardiomyopathy: all-cause mortality and heart failure. JACC Cardiovasc Imaging. 2016;9(1):40-50. 
87. Radenkovic D, Weingartner S, Ricketts L, Moon JC, Captur G. T1 mapping in cardiac MRI. Heart Fail Rev. 2017;22(4):415-30.

88. Youn JC, Hong YJ, Lee HJ, Han K, Shim CY, Hong GR, et al. Contrast-enhanced T1 mapping-based extracellular volume fraction independently predicts clinical outcome in patients with non-ischemic dilated cardiomyopathy: a prospective cohort study. Eur Radiol. 2017;27(9):3924-33.

89. Dass S, Suttie JJ, Piechnik SK, Ferreira VM, Holloway CJ, Banerjee R, et al. Myocardial tissue characterization using magnetic resonance noncontrast $\mathrm{t} 1$ mapping in hypertrophic and dilated cardiomyopathy. Circ Cardiovasc Imaging. 2012;5(6):726-33.

90. Puntmann VO, Arroyo Ucar E, Hinojar Baydes R, Ngah NB, Kuo YS, Dabir D, et al. Aortic stiffness and interstitial myocardial fibrosis by native $\mathrm{T} 1$ are independently associated with left ventricular remodeling in patients with dilated cardiomyopathy. Hypertension. 2014;64(4):762-8.

91. Kato S, Nakamori S, Roujol S, Delling FN, Akhtari S, Jang J, et al. Relationship between native papillary muscle $\mathrm{T} 1$ time and severity of functional mitral regurgitation in patients with non-ischemic dilated cardiomyopathy. J Cardiovasc Magn Reson. 2016;18(1):79.

92. Taylor RJ, Umar F, Lin EL, Ahmed A, Moody WE, Mazur W, et al. Mechanical effects of left ventricular midwall fibrosis in non-ischemic cardiomyopathy. J Cardiovasc Magn Reson. 2016;18:1.

93. Henn MC, Lawrance CP, Kar J, Cupps BP, Kulshrestha K, Koerner D, et al. Dilated cardiomyopathy: normalized multiparametric myocardial strain predicts contractile recovery. Ann Thorac Surg. 2015;100(4):1284-91.

94. Claus P, Omar AMS, Pedrizzetti G, Sengupta PP, Nagel E. Tissue tracking technology for assessing cardiac mechanics: principles, normal values, and clinical applications. J Am Coll Cardiol Img. 2015;8(12):1444-60.

95. Schuster A, Hor KN, Kowallick JT, Beerbaum P, Kutty S. Cardiovascular magnetic resonance myocardial feature tracking: concepts and clinical applications. Circ Cardiovasc Imaging. 2016;9(4):e004077.

96. Jeung MY, Germain P, Croisille P, El ghannudi S, Roy C, Gangi A. Myocardial tagging with MR imaging: overview of normal and pathologic findings. Radiographics. 2012;32(5):1381-98.

97. Pedrizzetti G, Claus P, Kilner PJ, Nagel E. Principles of cardiovascular magnetic resonance feature tracking and echocardiographic speckle tracking for informed clinical use. J Cardiovasc Magn Reson. 2016;18(1):51.

98. Yu Y, Yu S, Tang X, Ren H, Li S, Zou Q, et al. Evaluation of left ventricular strain in patients with dilated cardiomyopathy. J Int Med Res. 2017;45(6):2092-100.

99. Buss SJ, Breuninger K, Lehrke S, Voss A, Galuschky C, Lossnitzer D, et al. Assessment of myocardial deformation with cardiac magnetic resonance strain imaging improves risk stratification in patients with dilated cardiomyopathy. Eur Heart J Cardiovasc Imaging. 2015;16(3):307-15.

100. Romano S, Judd RM, Kim RJ, Kim HW, Klem I, Heitner J, et al. Association of featuretracking cardiac magnetic resonance imaging left ventricular global longitudinal strain with all-cause mortality in patients with reduced left ventricular ejection fraction. Circulation. 2017;135(23):2313-5.

101. Romano S, Judd RM, Kim RJ, Kim HW, Klem I, Heitner JF, et al. Feature-tracking global longitudinal strain predicts death in a multicenter population of patients with ischemic and nonischemic dilated cardiomyopathy incremental to ejection fraction and late gadolinium enhancement. JACC Cardiovasc Imaging. 2018; https://doi.org/10.1016/j. jcmg.2017.10.024.

102. Riffel JH, Keller MG, Rost F, Arenja N, Andre F, Aus dem Siepen F, et al. Left ventricular long axis strain: a new prognosticator in non-ischemic dilated cardiomyopathy? J Cardiovasc Magn Reson. 2016;18(1):36.

103. Cui Y, Cao Y, Song J, Dong N, Kong X, Wang J, et al. Association between myocardial extracellular volume and strain analysis through cardiovascular magnetic resonance with his- 
tological myocardial fibrosis in patients awaiting heart transplantation. J Cardiovasc Magn Reson. 2018;20(1):25.

104. Merlo M, Masè M, Vitrella G, Belgrano M, Faganello G, Di Giusto F, et al. Usefulness of addition of magnetic resonance imaging to echocardiographic imaging to predict left ventricular reverse remodeling in patients with non-ischemic cardiomyopathy. Am J Cardiol. 2018; https://doi.org/10.1016/j.amjcard.2018.04.017.

105. Bilchick KC, Dimaano V, Wu KC, Helm RH, Weiss RG, Lima JA, et al. Cardiac magnetic resonance assessment of dyssynchrony and myocardial scar predicts function class improvement following cardiac resynchronization therapy. JACC Cardiovasc Imaging. 2008;1(5):561-8.

106. Ponikowski P, Voors AA, Anker SD, Bueno H, Cleland JGF, Coats AJS, et al. 2016 ESC GUIDELINES for the diagnosis and treatment of acute and chronic heart failure: The Task Force for the diagnosis and treatment of acute and chronic heart failure of the European Society of Cardiology (ESC)Developed with the special contribution of the Heart Failure Association (HFA) of the ESC. Eur Heart J. 2016;37(27):2129-200.

107. Juilliere Y, Barbier G, Feldmann L, Grentzinger A, Danchin N, Cherrier F. Additional predictive value of both left and right ventricular ejection fractions on long-term survival in idiopathic dilated cardiomyopathy. Eur Heart J. 1997;18(2):276-80.

108. La Vecchia L, Paccanaro M, Bonanno C, Varotto L, Ometto R, Vincenzi M. Left ventricular versus biventricular dysfunction in idiopathic dilated cardiomyopathy. Am J Cardiol. 1999;83(1):120-2, A9.

109. Gulati A, Ismail TF, Jabbour A, Alpendurada F, Guha K, Ismail NA, et al. The prevalence and prognostic significance of right ventricular systolic dysfunction in nonischemic dilated cardiomyopathy. Circulation. 2013;128(15):1623-33.

110. Arenja N, Riffel JH, Halder M, Djiokou CN, Fritz T, Andre F, et al. The prognostic value of right ventricular long axis strain in non-ischaemic dilated cardiomyopathies using standard cardiac magnetic resonance imaging. Eur Radiol. 2017;27(9):3913-23.

111. Dini FL, Cortigiani L, Baldini U, Boni A, Nuti R, Barsotti L, et al. Prognostic value of left atrial enlargement in patients with idiopathic dilated cardiomyopathy and ischemic cardiomyopathy. Am J Cardiol. 2002;89(5):518-23.

112. Rossi A, Temporelli PL, Quintana M, Dini FL, Ghio S, Hillis GS, et al. Independent relationship of left atrial size and mortality in patients with heart failure: an individual patient meta-analysis of longitudinal data (MeRGE Heart Failure). Eur J Heart Fail. 2009;11(10):929-36.

113. Tsang MY, Barnes ME, Tsang TS. Left atrial volume: clinical value revisited. Curr Cardiol Rep. 2012;14(3):374-80.

114. Gulati A, Ismail TF, Jabbour A, Ismail NA, Morarji K, Ali A, et al. Clinical utility and prognostic value of left atrial volume assessment by cardiovascular magnetic resonance in nonischaemic dilated cardiomyopathy. Eur J Heart Fail. 2013;15(6):660-70.

115. Moon J, Shim CY, Kim YJ, Park S, Kang SM, Chung N, et al. Left atrial volume as a predictor of left ventricular functional recovery in patients with dilated cardiomyopathy and absence of delayed enhancement in cardiac magnetic resonance. J Card Fail. 2016;22(4):265-71.

116. Amzulescu MS, Rousseau MF, Ahn SA, Boileau L, de Meester de Ravenstein C, Vancraeynest $\mathrm{D}$, et al. Prognostic impact of hypertrabeculation and noncompaction phenotype in dilated cardiomyopathy: a CMR study. J Am Coll Cardiol Img. 2015;8(8):934-46.

117. Abunassar JG, Yam Y, Chen L, D'Mello N, Chow BJ. Usefulness of the Agatston score $=0$ to exclude ischemic cardiomyopathy in patients with heart failure. Am J Cardiol. 2011;107(3):428-32.

118. Sousa PA, Bettencourt N, Dias Ferreira N, Carvalho M, Leite D, Ferreira W, et al. Role of cardiac multidetector computed tomography in the exclusion of ischemic etiology in heart failure patients. Rev Port Cardiol. 2014;33(10):629-36.

119. Raff GL, Gallagher MJ, O'Neill WW, Goldstein JA. Diagnostic accuracy of noninvasive coronary angiography using 64-slice spiral computed tomography. J Am Coll Cardiol. 2005;46(3):552-7. 
120. Andreini D, Pontone G, Pepi M, Ballerini G, Bartorelli AL, Magini A, et al. Diagnostic accuracy of multidetector computed tomography coronary angiography in patients with dilated cardiomyopathy. J Am Coll Cardiol. 2007;49(20):2044-50.

121. Ghostine S, Caussin C, Habis M, Habib Y, Clement C, Sigal-Cinqualbre A, et al. Noninvasive diagnosis of ischaemic heart failure using 64-slice computed tomography. Eur Heart J. 2008;29(17):2133-40.

122. Bhatti S, Hakeem A, Yousuf MA, Al-Khalidi HR, Mazur W, Shizukuda Y. Diagnostic performance of computed tomography angiography for differentiating ischemic vs nonischemic cardiomyopathy. J Nucl Cardiol. 2011;18(3):407-20.

123. Mowatt G, Cook JA, Hillis GS, Walker S, Fraser C, Jia X, et al. 64-Slice computed tomography angiography in the diagnosis and assessment of coronary artery disease: systematic review and meta-analysis. Heart. 2008;94(11):1386-93.

124. de Graaf FR, Schuijf JD, van Velzen JE, Boogers MJ, Kroft LJ, de Roos A, et al. Diagnostic accuracy of 320-row multidetector computed tomography coronary angiography to noninvasively assess in-stent restenosis. Invest Radiol. 2010;45(6):331-40.

125. Guo SL, Guo YM, Zhai YN, Ma B, Wang P, Yang KH. Diagnostic accuracy of first generation dual-source computed tomography in the assessment of coronary artery disease: a metaanalysis from 24 studies. Int J Cardiovasc Imaging. 2011;27(6):755-71.

126. Juergens KU, Grude M, Maintz D, Fallenberg EM, Wichter T, Heindel W, et al. Multidetector row CT of left ventricular function with dedicated analysis software versus MR imaging: initial experience. Radiology. 2004;230(2):403-10.

127. Lessick J, Mutlak D, Rispler S, Ghersin E, Dragu R, Litmanovich D, et al. Comparison of multidetector computed tomography versus echocardiography for assessing regional left ventricular function. Am J Cardiol. 2005;96(7):1011-5.

128. Yamamuro M, Tadamura E, Kubo S, Toyoda H, Nishina T, Ohba M, et al. Cardiac functional analysis with multi-detector row $\mathrm{CT}$ and segmental reconstruction algorithm: comparison with echocardiography, SPECT, and MR imaging. Radiology. 2005;234(2):381-90.

129. Burianova L, Riedlbauchova L, Lefflerova K, Marek T, Lupinek P, Kautznerova D, et al. Assessment of left ventricular function in non-dilated and dilated hearts: comparison of contrast-enhanced 2-dimensional echocardiography with multi-detector row CT angiography. Acta Cardiol. 2009;64(6):787-94.

130. Kang DK, Schoepf UJ, Bastarrika G, Nance JW Jr, Abro JA, Ruzsics B. Dual-energy computed tomography for integrative imaging of coronary artery disease: principles and clinical applications. Semin Ultrasound CT MR. 2010;31(4):276-91.

131. Ko SM, Choi JW, Song MG, Shin JK, Chee HK, Chung HW, et al. Myocardial perfusion imaging using adenosine-induced stress dual-energy computed tomography of the heart: comparison with cardiac magnetic resonance imaging and conventional coronary angiography. Eur Radiol. 2011;21(1):26-35.

132. Wang R, Yu W, Wang Y, He Y, Yang L, Bi T, et al. Incremental value of dual-energy CT to coronary $\mathrm{CT}$ angiography for the detection of significant coronary stenosis: comparison with quantitative coronary angiography and single photon emission computed tomography. Int J Cardiovasc Imaging. 2011;27(5):647-56.

133. Ko SM, Park JH, Hwang HK, Song MG. Direct comparison of stress- and rest-dual-energy computed tomography for detection of myocardial perfusion defect. Int $\mathbf{J}$ Cardiovasc Imaging. 2014;30(Suppl 1):41-53.

134. Osawa K, Miyoshi T, Koyama Y, Hashimoto K, Sato S, Nakamura K, et al. Additional diagnostic value of first-pass myocardial perfusion imaging without stress when combined with 64-row detector coronary CT angiography in patients with coronary artery disease. Heart. 2014;100(13):1008-15.

135. Varga-Szemes A, Meinel FG, De Cecco CN, Fuller SR, Bayer RR II, Schoepf UJ. CT myocardial perfusion imaging. AJR Am J Roentgenol. 2015;204(3):487-97.

136. Zhao L, Ma X, Feuchtner GM, Zhang C, Fan Z. Quantification of myocardial delayed enhancement and wall thickness in hypertrophic cardiomyopathy: multidetector computed tomography versus magnetic resonance imaging. Eur J Radiol. 2014;83(10):1778-85. 
137. Nieman K, Shapiro MD, Ferencik M, Nomura CH, Abbara S, Hoffmann U, et al. Reperfused myocardial infarction: contrast-enhanced 64-Section CT in comparison to MR imaging. Radiology. 2008;247(1):49-56.

138. Wichmann JL, Arbaciauskaite R, Kerl JM, Frellesen C, Bodelle B, Lehnert T, et al. Evaluation of monoenergetic late iodine enhancement dual-energy computed tomography for imaging of chronic myocardial infarction. Eur Radiol. 2014;24(6):1211-8.

139. Esposito A, Palmisano A, Antunes S, Maccabelli G, Colantoni C, Rancoita PMV, et al. Cardiac CT with delayed enhancement in the characterization of ventricular tachycardia structural substrate: relationship between CT-segmented scar and electro-anatomic mapping. J Am Coll Cardiol Img. 2016;9(7):822-32.

140. Cerny V, Kuchynka P, Marek J, Lambert L, Masek M, Palecek T, et al. Utility of cardiac CT for evaluating delayed contrast enhancement in dilated cardiomyopathy. Herz. 2017;42(8):776-80.

141. Nacif MS, Kawel N, Lee JJ, Chen X, Yao J, Zavodni A, et al. Interstitial myocardial fibrosis assessed as extracellular volume fraction with low-radiation-dose cardiac CT. Radiology. 2012;264(3):876-83.

142. Nacif MS, Liu Y, Yao J, Liu S, Sibley CT, Summers RM, et al. 3D left ventricular extracellular volume fraction by low-radiation dose cardiac CT: assessment of interstitial myocardial fibrosis. J Cardiovasc Comput Tomogr. 2013;7(1):51-7.

143. Wichmann JL, Hu X, Kerl JM, Schulz B, Bodelle B, Frellesen C, et al. Non-linear blending of dual-energy CT data improves depiction of late iodine enhancement in chronic myocardial infarction. Int J Cardiovasc Imaging. 2014;30(6):1145-50.

144. Chang S, Han K, Youn JC, Im DJ, Kim JY, Suh YJ, et al. Utility of dual-energy CT-based monochromatic imaging in the assessment of myocardial delayed enhancement in patients with cardiomyopathy. Radiology. 2018;287(2):442-51.

145. Wolk MJ, Bailey SR, Doherty JU, Douglas PS, Hendel RC, Kramer CM, et al. ACCF/ AHA/ASE/ASNC/HFSA/HRS/SCAI/SCCT/SCMR/STS 2013 multimodality appropriate use criteria for the detection and risk assessment of stable ischemic heart disease: a report of the American College of Cardiology Foundation Appropriate Use Criteria Task Force, American Heart Association, American Society of Echocardiography, American Society of Nuclear Cardiology, Heart Failure Society of America, Heart Rhythm Society, Society for Cardiovascular Angiography and Interventions, Society of Cardiovascular Computed Tomography, Society for Cardiovascular Magnetic Resonance, and Society of Thoracic Surgeons. J Am Coll Cardiol. 2014;63(4):380-406.

146. Garbi M, Edvardsen T, Bax J, Petersen SE, McDonagh T, Filippatos G, et al. EACVI appropriateness criteria for the use of cardiovascular imaging in heart failure derived from European National Imaging Societies voting. Eur Heart J Cardiovasc Imaging. 2016;17(7):711-21.

Open Access This chapter is licensed under the terms of the Creative Commons Attribution 4.0 International License (http://creativecommons.org/licenses/by/4.0/), which permits use, sharing, adaptation, distribution and reproduction in any medium or format, as long as you give appropriate credit to the original author(s) and the source, provide a link to the Creative Commons license and indicate if changes were made.

The images or other third party material in this chapter are included in the chapter's Creative Commons license, unless indicated otherwise in a credit line to the material. If material is not included in the chapter's Creative Commons license and your intended use is not permitted by statutory regulation or exceeds the permitted use, you will need to obtain permission directly from the copyright holder.

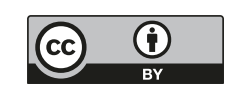

